九州大学学術情報リポジトリ

Kyushu University Institutional Repository

\title{
Epitaxial growth of large-area single-layer graphene over Cu(111)/sapphire by atmospheric pressure CVD
}

$\mathrm{Hu}$, Baoshan

Institute for Materials Chemistry and Engineering, Kyushu University

Ago, Hiroki

Graduate School of Engineering Sciences, Kyushu University | Institute for Materials Chemistry and Engineering, Kyushu University

Ito, Yoshito

Graduate School of Engineering Sciences, Kyushu University

Kawahara, Ken j i

Institute for Materials Chemistry and Engineering, Kyushu University

他

http://hdl. hand le. net/2324/27288

出版情報：Carbon. 50 (1)，pp.57-65，2012-01. Elsevier

バージョン：

権利関係: (C) 2011 Elsevier Ltd. 


\title{
Epitaxial growth of large-area single-layer graphene over $\mathrm{Cu}(111) / s a p p h i r e$ by atmospheric pressure CVD
}

\author{
Baoshan Hu, ${ }^{a}$ Hiroki Ago,,${ }^{\text {a,b }}$ Yoshito Ito, ${ }^{\mathrm{b}}$ Kenji Kawahara, ${ }^{\mathrm{a}}$ Masaharu Tsuji, ${ }^{\mathrm{a}, \mathrm{b}}$ \\ Eisuke Magome, ${ }^{\mathrm{c}}$ Kazushi Sumitani, ${ }^{\mathrm{c}}$ Noriaki Mizuta, ${ }^{\mathrm{b}}$ Ken-ichi Ikeda, ${ }^{\mathrm{b}}$ and Seigi Mizuno ${ }^{\mathrm{b}}$ \\ a Institute for Materials Chemistry and Engineering, Kyushu University, Kasuga, Fukuoka \\ 816-8580, Japan \\ b Graduate School of Engineering Sciences, Kyushu University, Kasuga, Fukuoka 816-8580, \\ Japan \\ c Kyushu Synchrotron Light Center, Saga, 841-0005, Japan
}

We report the atmospheric pressure chemical vapor deposition (CVD) growth of single-layer graphene over a crystalline $\mathrm{Cu}(111)$ film heteroepitaxially deposited on c-plane sapphire. Orientation-controlled, epitaxial single-layer graphene is achieved over the $\mathrm{Cu}(111)$ film on sapphire, while a polycrystalline $\mathrm{Cu}$ film deposited on a $\mathrm{Si}$ wafer gives non-uniform graphene with multi-layer flakes. Moreover, the CVD temperature is found to affect the quality and orientation of graphene grown on the $\mathrm{Cu} / \mathrm{sapphire}$ substrates. The CVD growth at $1000{ }^{\circ} \mathrm{C}$ gives high-quality epitaxial single-layer graphene whose orientation of hexagonal lattice matches with the $\mathrm{Cu}(111)$ lattice which is determined by the sapphire's crystallographic direction. At lower CVD temperature of $900{ }^{\circ} \mathrm{C}$, low-quality graphene with enhanced Raman D band is obtained, and it showed two different orientations of the hexagonal lattice; one matches with the $\mathrm{Cu}$ lattice and another rotated by $30^{\circ}$. Carbon isotope-labeling experiment indicates rapid exchange of the surface-adsorbed and gas-supplied carbon atoms at the higher temperature, resulting in the highly crystallized graphene with energetically most stable orientation consistent with the underlying $\mathrm{Cu}(111)$ lattice.

\footnotetext{
* Corresponding author: Fax: +81-92-583-7817, E-mail: ago@ cm.kyushu-u.ac.jp (H. Ago)
} 


\section{Introduction}

Graphene is a two dimensional crystalline sheet of carbon atoms arranged in a honeycomb lattice that shows various fascinating physical properties, such as quantum Hall effect at room temperature, a tunable band gap, extremely high mobility, and high elasticity [1-4]. These properties promise applications in future electronics, such as transistors, transparent electrodes, liquid crystal devices, and supercapacitors [5-8]. Therefore, preparation of high-quality graphene sheets with low cost as well as integration with other materials has been attracting much attention. Since the graphene prepared by mechanical exfoliation of bulk graphite is limited in the uniformities of size, structure, and film thickness, several other approaches have been developed to synthesize graphene [10]. High temperature annealing of single crystalline $\mathrm{SiC}(0001)$ leads to the formation of epitaxial graphene, but the $\mathrm{SiC}$ substrates are expensive and it is difficult to transfer the epitaxial graphene onto other substrates [10-11]. Self-assembly of solution-based exfoliated graphite and graphite oxide could achieve continuous and low-cost graphene films $[6,12,13]$, but it suffers from many structural defects and, thus, one cannot expect the intrinsic transport properties of graphene film [14].

Chemical vapor deposition (CVD) over transition metals have attracted a great interest as an effective and powerful means to prepare easily-transferrable, high quality graphene films. Most of the CVD growth uses polycrystalline Ni [15-20], Fe [21], and $\mathrm{Cu}$ [22-26] films/foils, and it has been considered that $\mathrm{Ni}$ and $\mathrm{Fe}$ gives inhomogeneous graphene films with multi-layer flaks, while $\mathrm{Cu}$ gives single-layer graphene due to low carbon solubility [22,27]. Although control of the orientation of hexagonal lattice of graphene is essential for studying the transport property and for graphene engineering, most CVD research works obtain graphene with random orientation of hexagonal lattice of graphene (i.e. different orientation in each graphene domain [28]) due to polycrystallinity of catalytic metal films/foils. Single crystalline metal substrates, such as $\mathrm{Ni}(111), \mathrm{Ru}(0001)$, and $\operatorname{Ir}(111)$, enables the orientation-controlled growth, because graphene forms commensurate structure with these metal surfaces [29-33]. However, these substrates are limited in size and very expensive so that they are not suitable for practical applications. In addition, ultra-high vacuum chamber 
is used to grow single-layer graphene for these crystalline substrates, again, limiting the size and scalability of the graphene synthesis.

More promising and practical approach is to use metal films heteroepitaxially deposited on conventional single crystalline substrates. We demonstrated that the heteroepitaxial Co films on $\mathrm{MgO}(100)$ and $\mathrm{MgO}(111)$ substrates can be used to graphene growth, but rectangular and triangular pits which appeared on the Co surface stimulated the graphene growth inside them [34]. Very recently, this approach has been further developed to make uniform single-layer graphene over heteroepitaxial $\mathrm{Co}, \mathrm{Ni}$, and $\mathrm{Ru}$ films [35-37]. It was demonstrated that even $\mathrm{Co}$ and $\mathrm{Ni}$, which have relatively high carbon solubility, can catalyze the growth of uniform single-layer graphene when the crystallinity is high enough $[35,36]$. However, the graphene films transferred from these crystallized Co and Ni films showed a relatively strong Raman D band at $\sim 1350 \mathrm{~cm}^{-1}$, signifying the presence of significant amount of defects $[35,36]$. We speculate that this is accounted for by strong interaction between these catalyst metals and graphene [35]. Calculations based on density functional theory indicates that $\mathrm{Co}$ and $\mathrm{Ni}$ have much higher binding energies $(0.160$ and $0.125 \mathrm{eV}$, respectively) with graphene than $\mathrm{Cu}(0.033 \mathrm{eV})$ [38]. The experimental analysis for the graphene grown on a single crystalline $\mathrm{Ni}(111)$ suggests significant hybridization between $\mathrm{Ni}$ and $\mathrm{C}$ atomic orbitals based on the observed short graphene-Ni distance [29]. Therefore, the chemical etching used for the graphene transfer would give rise to the formation of dangling bonds. Because the chemical etching is done in aqueous solution, these dangling bonds are likely to form $\mathrm{sp}^{3}$-carbon atoms that can be terminated with, for example, hydrogen or hydroxyl, carboxylic groups. The presence of these $\mathrm{sp}^{3}$-carbon atoms makes graphene domain smaller with many edges that could induce the strong Raman D band. The graphene formed on heteroepitaxial $\mathrm{Ru}$ film also showed strong $\mathrm{D}$ band after the transfer, which suggests difficulty in etching the chemically inert Ru metal without avoiding the damage to graphene [37].

Here, we report atmospheric pressure CVD growth of large area graphene on crystalline $\mathrm{Cu}(111)$ film which is heteroepitaxially deposited on c-plane sapphire $\left(\alpha-\mathrm{Al}_{2} \mathrm{O}_{3}\right)$. The graphene transferred from the $\mathrm{Cu}(111)$ shows negligible $\mathrm{D}$ band, signifying higher quality 
than that transferred from the Co/sapphire substrate. Moreover, the orientation of hexagonal lattice of graphene matches with the underneath $\mathrm{Cu}(111)$ lattice. We also show temperature-dependent graphene growth based on carbon isotope labeling experiments.

\section{Experimental}

\subsection{Synthesis and transfer of graphene film}

$\mathrm{Cu}$ films (500 nm thickness) were deposited onto c-plane $\alpha-\mathrm{Al}_{2} \mathrm{O}_{3}$ and $\mathrm{SiO}_{2}(300 \mathrm{~nm}) / \mathrm{Si}$ substrates with a power of $300 \mathrm{~W}$ in Ar atmosphere $(0.6 \mathrm{~Pa})$ by a radio frequency (RF) magnetron sputtering machine (Shibaura Mechatoronics Corp., CFS-4ES). For CVD, as-sputtered $\mathrm{Cu}$ film was placed on a quartz sample holder with magnetic handle for the purpose of rapid cooling, and then inserted into a horizontal quartz tube. The substrate was heated up in the quartz tube and annealed for 60 min under ambient pressure with a gas flow of $\mathrm{H}_{2} / \mathrm{Ar}$ (volume concentrations of $\mathrm{H}_{2}$ are $~ 2 \%$ at both $900{ }^{\circ} \mathrm{C}$ and $1000{ }^{\circ} \mathrm{C}$ ), followed by introducing $\mathrm{CH}_{4}$ gas for $10 \mathrm{~min}$ (the volume ratios of $\mathrm{CH}_{4} / \mathrm{H}_{2} / \mathrm{Ar}$ are $4 / 2 / 94$ at $900{ }^{\circ} \mathrm{C}$, and 0.4/2/97.6 at $1000{ }^{\circ} \mathrm{C}$, respectively). Finally, the sample was rapidly cooled down to room temperature by moving the sample holder to outside the furnace with a magnet under the $\mathrm{H}_{2} /$ Ar flow.

The transfer process is similar to the previous report [34]. In brief, after the CVD, the substrate surface was covered with PMMA by spin-coating. Thermal tape (Revalpha, Nitto Denko) was attached onto the PMMA film. Then, the $\mathrm{Cu}$ film was dissolved in $\mathrm{FeCl}_{3} / \mathrm{HCl}$ aqueous solution to release the graphene supported with PMMA and thermal tape. Subsequently, the thermal tape/PMMA/graphene was washed with deionized water and transferred onto a target $\mathrm{SiO}_{2} / \mathrm{Si}$ substrate, and then baked at $120{ }^{\circ} \mathrm{C}$ for $30 \mathrm{~min}$. Finally, the thermal tape and PMMA were removed together by acetone, leaving the graphene film on the $\mathrm{SiO}_{2} / \mathrm{Si}$ substrate.

\subsection{Characterization}

Raman spectra and mapping images of graphene films were measured with JASCO NRS-2100 using $514.5 \mathrm{~nm}$ excitation wavelength. Transmission electron microscope (TEM) 
images of samples which were sliced with a focused ion beam (FIB, HITACHI NB 5000) were measured with a HITACHI H-9500 at $300 \mathrm{keV}$ acceleration voltage. Atomic force microscope (AFM) images were measured with a Bruker, Nanoscope IIIa. The crystallinity and crystallographic orientation of $\mathrm{Cu}$ films were measured by an X-ray diffraction (XRD) (RIGAKU RINT 2500) and synchrotron XRD at SAGA Light Source (beamline BL15). The crystal phase was identified by a scanning electron microscope (SEM, Zeiss Ultra55) equipped with an electron backscatter diffraction (EBSD, TSL Solutions OIM). Low energy electron diffraction (LEED) patterns of as-grown graphene were recorded in an ultra high vacuum chamber with a pressure of $<8 \times 10^{-9}$ Pa equipped with a LEED optics (OMICRON SPECTALEED).

\section{Results and discussion}

\subsection{Crystallographic characterizations of $\mathrm{Cu}$ films}

First, we examined the crystallinity of a $\mathrm{Cu}$ film, because a $\mathrm{Cu}$ film plays an essential role in catalytic growth of graphene. After CVD growth, XRD measurements were performed for the $\mathrm{Cu}$ films deposited on sapphire c-plane and $\mathrm{SiO}_{2}(300 \mathrm{~nm}) / \mathrm{Si}$ substrates. As shown in Fig. 1a and Supplementary Material (Fig. S-1a), the $\mathrm{Cu}$ films on sapphire showed clear diffraction peaks solely from $\mathrm{Cu}(111)\left(2 \theta=43.4^{\circ}\right)$, while the $\mathrm{Cu} / \mathrm{SiO}_{2} / \mathrm{Si}$ sample gave two peaks from $\mathrm{Cu}(111)$ and $\mathrm{Cu}(200)\left(2 \theta=50.6^{\circ}\right)$. Since the as-grown graphene was very thin, no diffraction peak from graphene was detected. The present XRD data indicate that the crystalline $\mathrm{Cu}$ phase is realized on c-plane sapphire with the crystallographic $\mathrm{Cu}(111)$ orientation parallel to $\mathrm{Al}_{2} \mathrm{O}_{3}(0001)$, while the $\mathrm{Cu}$ on $\mathrm{SiO}_{2} / \mathrm{Si}$ is polycrystalline.

To confirm epitaxial relationship of $\mathrm{Cu}(111)$ with the sapphire, we chose $\mathrm{Cu} 200$ as Bragg position and performed a $\varphi$ scan by rotating the sample normal to the surface with synchrotron XRD. As shown in Figs. $1 \mathrm{~b}$ and $\mathrm{S}-1 \mathrm{~b}$, the diffraction peaks appear periodically at intervals of $60^{\circ}$ and have quite narrow full width at half maximum (FWHM), proving that $\mathrm{Cu}$ films were epitaxially grown on the sapphire substrates. Since a single [111] pole has a three-fold trigonal symmetry, it is highly likely that the observed six-fold symmetry results from two sets of $\mathrm{Cu}(111)$ crystallites with azimuthal orientation $60^{\circ}$ apart [39]. We also 
measured the Bragg diffractions of sapphire 0224 to investigate the crystallographic relationship between $\mathrm{Cu}$ film and c-plane sapphire and obtained the epitaxial relationship, expressed as $\mathrm{Cu}(111)[211] / / \mathrm{Al}_{2} \mathrm{O}_{3}(0001)$ [2110], consistent with previous literature [39,40]. On the contrary, the $\mathrm{Cu}$ film deposited on the $\mathrm{SiO}_{2} / \mathrm{Si}$ substrate showed no epitaxial geometry (see Fig. 1c).
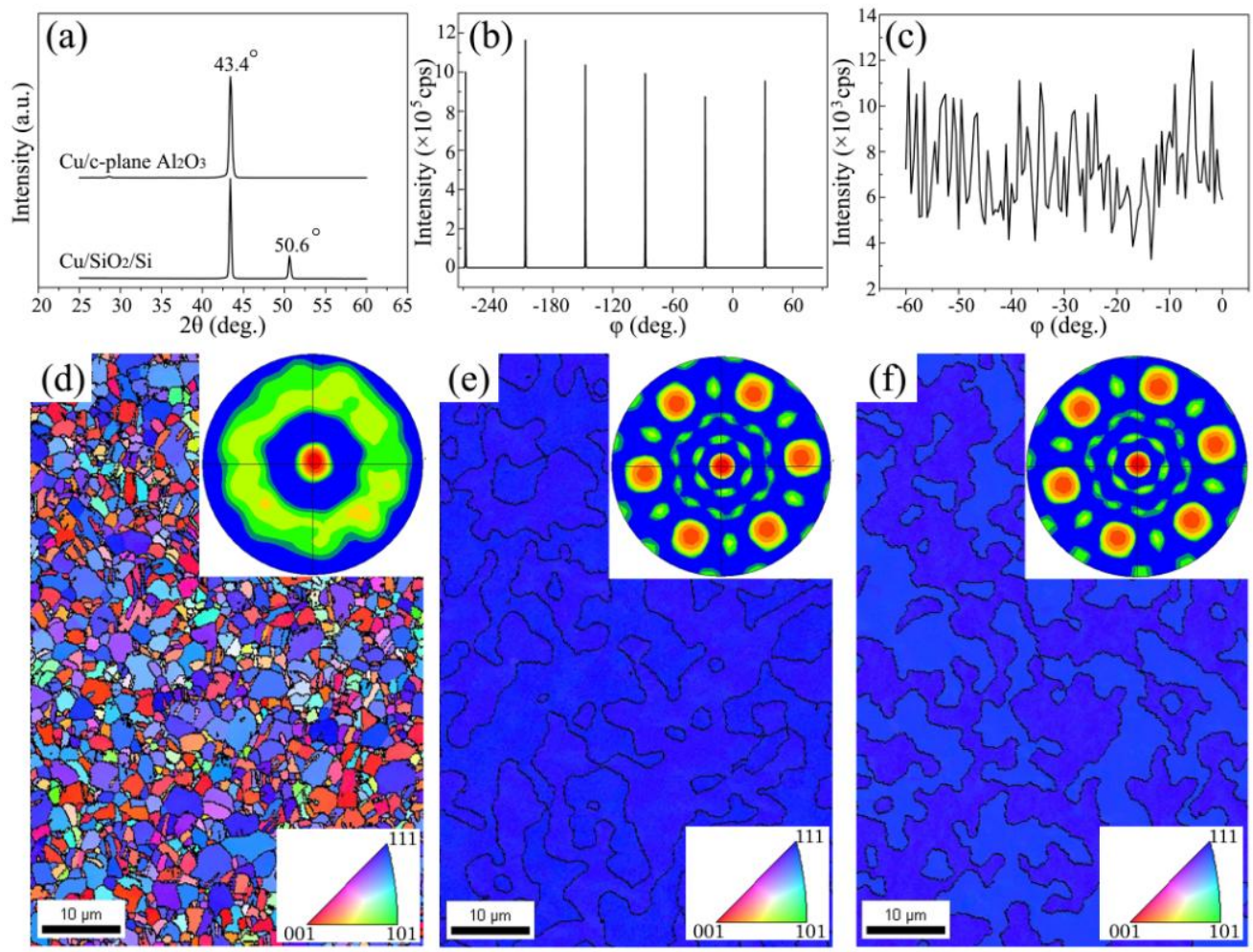

Fig. 1 Crystallographic characterizations of $\mathrm{Cu}$ films deposited on c-plane sapphire and $\mathrm{SiO}_{2} / \mathrm{Si}$ substrates measured after CVD. (a) $\theta-2 \theta$ profiles of XRD of these $\mathrm{Cu}$ films. $\varphi$ scan profiles of XRD of $\mathrm{Cu} / \mathrm{sapphire} \mathrm{(b)} \mathrm{and} \mathrm{Cu} / \mathrm{SiO}_{2} / \mathrm{Si}$ (c). The samples were measured after $900{ }^{\circ} \mathrm{C}$ CVD. Crystal orientation distributions and [111] pole figures (inset) of $\mathrm{Cu} / \mathrm{SiO}_{2} / \mathrm{Si}$ after $900{ }^{\circ} \mathrm{C} \mathrm{CVD} \mathrm{(d),} \mathrm{Cu} /$ sapphire after $900{ }^{\circ} \mathrm{C} \mathrm{CVD}$ (e), and $\mathrm{Cu} /$ sapphire after $1000{ }^{\circ} \mathrm{C} \mathrm{CVD} \mathrm{(f).}$

To identify the crystal texture of $\mathrm{Cu}$ films, we performed EBSD measurement (Fig. 1d-f). As seen in Fig. 1d, the $\mathrm{Cu}$ film on the $\mathrm{SiO}_{2} / \mathrm{Si}$ substrate shows a number of small grains with different crystallographic orientations, and the corresponding [111] pole figure (inset) shows a ring pattern. The data indicates the polycrystalline nature of the $\mathrm{Cu}$ film due to underneath 
amorphous $\mathrm{SiO}_{2}$ surface layer. The $\mathrm{Cu}$ films on sapphire (Fig. 1e,f) exhibit similar shades with blue color, corresponding to the same crystalline $\mathrm{Cu}(111)$ with no significant difference for 900 and $1000{ }^{\circ} \mathrm{C} \mathrm{CVD}$ samples. One can see boundaries between two kinds of $\mathrm{Cu}(111)$ grains, revealing the different crystallographic orientations of the $\mathrm{Cu}(111)$ grains. This represents twin structure of the $\mathrm{Cu}$ films. The [111] pole figures (Fig. 1e,f insets) showed the six-fold symmetrical patterns at intervals of $60^{\circ}$, indicating that the two kinds of $\mathrm{Cu}(111)$ grains are rotated by $60^{\circ}$. These six-fold symmetrical patterns are consistent with the above $\mathrm{X}$-ray $\varphi$ scan profiles. The $\mathrm{Cu}$ grain size can be estimated to $\sim 10 \mu \mathrm{m}$ which is much larger than that of the $\mathrm{Cu}$ on $\mathrm{SiO}_{2} / \mathrm{Si}$ substrate $(1 \sim 2 \mu \mathrm{m})$.

\subsection{Atmospheric pressure CVD growth}

Although the vacuum CVD process has been widely used for $\mathrm{Cu}$ catalysts [22-24], atmospheric pressure CVD growth of high-quality single-layer is demanded, because the atmospheric CVD is applicable to large-scale graphene growth with low cost $[25,26]$. In addition, the thermal evaporation of $\mathrm{Cu}$, which contaminates the CVD chamber, is significantly reduced by increasing the growth pressure. Our atmospheric pressure CVD was performed using the optimized $\mathrm{CH}_{4} / \mathrm{H}_{2} / \mathrm{Ar}$ flow for $10 \mathrm{~min}$ at $900{ }^{\circ} \mathrm{C}$ or $1000{ }^{\circ} \mathrm{C}$. The graphene films were routinely transferred onto a target $\mathrm{SiO}_{2} / \mathrm{Si}$ substrate by using PMMA and etching solution for reliable characterizations. Figure 2 compares effects of substrates and CVD temperature on the $\mathrm{Cu}$ surface and the transferred graphene film. One can see that the $\mathrm{Cu}$ on c-plane sapphire exhibits much smoother surfaces than the $\mathrm{Cu} / \mathrm{SiO}_{2} / \mathrm{Si}$. This suggests that the $\mathrm{Cu}$ film deposited on sapphire is more stable than that on $\mathrm{SiO}_{2} / \mathrm{Si}$ due to the higher crystallinity of $\mathrm{Cu}$ metal as seen in Fig. 1d-f. The optical microscope images taken after the transfer also show clear difference between the graphene films grown on $\mathrm{Cu} / \mathrm{sapphire}$ and $\mathrm{Cu} / \mathrm{SiO}_{2} / \mathrm{Si}$; the former appear homogeneous, but the latter contains a large fraction of multi-layer graphene flakes which looks darker in the micrograph. These results suggest that graphene nucleation preferentially takes place at the grain boundaries of $\mathrm{Cu}$ film and that the graphene growth cannot be simply explained by the surface self-limiting mechanism [23] at least for our atmospheric pressure CVD. The result indicates that the crystalline $\mathrm{Cu}(111)$ 
film is favorable for the growth of uniform graphene rather than the polycrystalline one. We note that the graphene grown at $900{ }^{\circ} \mathrm{C}$ over $\mathrm{Cu}$ /sapphire contains few-layer graphene areas (Fig. 2e), while the graphene grown at $1000{ }^{\circ} \mathrm{C}$ is more uniform without clear contrast (Fig. 2f).
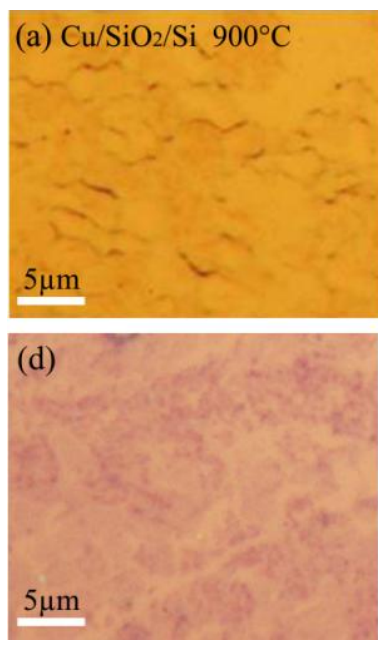

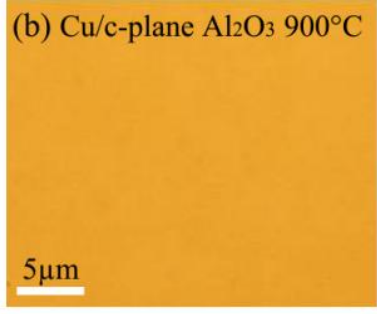

(e)

$5 \mu \mathrm{m}$

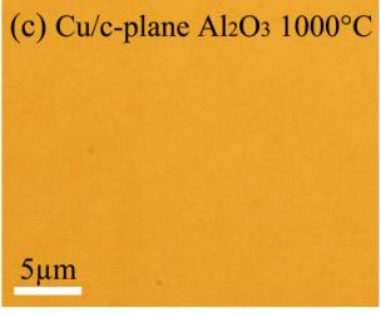

(f)

$5 \mu \mathrm{m}$

Fig. 2 Optical micrographs of the surfaces of $\mathrm{Cu} / \mathrm{SiO}_{2} / \mathrm{Si}$ (a) and $\mathrm{Cu} / \mathrm{sapphire}$ (b) after the CVD at $900{ }^{\circ} \mathrm{C}$, and that of $\mathrm{Cu} /$ sapphire after the CVD at $1000{ }^{\circ} \mathrm{C}$ (c). (d-f) optical micrographs of graphene films transferred from (a-c), respectively.

Figure 3a-c displays surface morphologies of the as-sputtered $\mathrm{Cu}$ film on sapphire and that after $\mathrm{CVD}$, measured by AFM. The as-sputtered $\mathrm{Cu}$ film shows very rough surface together with a number of $\mathrm{Cu}$ particles, but the CVD process was found to smoothen the surface although micrometer-scale roughness newly appeared. This surface smoothing is more clearly seen for $1000{ }^{\circ} \mathrm{C}$ CVD sample. The formation of graphene layer at high temperature as well as $\mathrm{H}_{2}$ reduction is considered to contribute to flatten the $\mathrm{Cu}$ surface, as was claimed by Mun et al. [41]. Figure 3d shows a cross-sectional TEM image for the as-grown graphene on $\mathrm{Cu}$, where single-layer graphene is observed. 

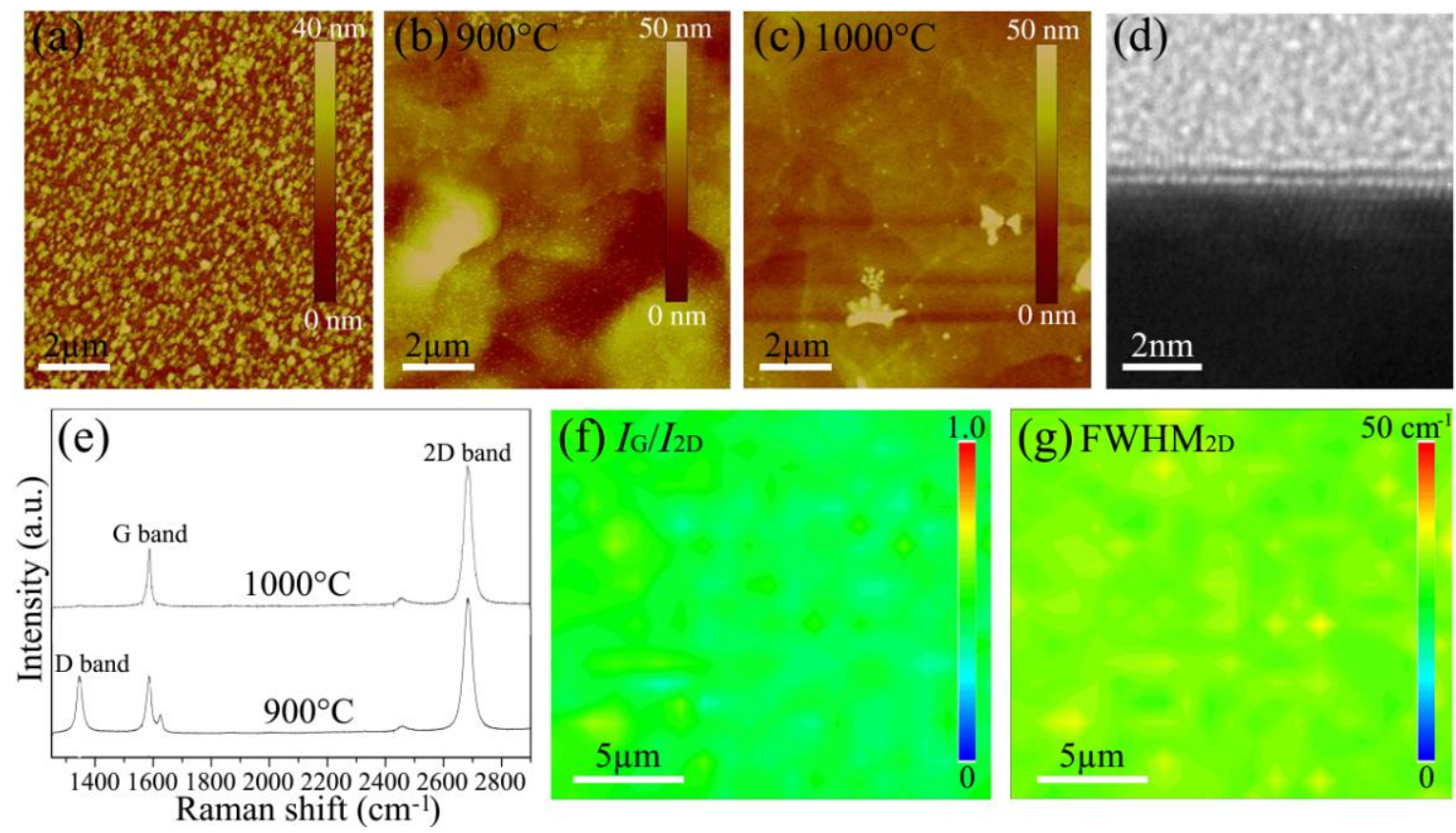

Fig. 3 AFM images of surfaces of as-sputtered $\mathrm{Cu}$ film on sapphire (a), and graphene/Cu/sapphire samples grown at $900{ }^{\circ} \mathrm{C}$ (b) and $1000{ }^{\circ} \mathrm{C}$ (c). (d) Cross-sectional TEM image of as-grown graphene/Cu/sapphire sample at $900{ }^{\circ} \mathrm{C} \mathrm{CVD}$. (e) Representative Raman spectra of transferred graphene films grown at 900 and $1000{ }^{\circ} \mathrm{C}$. Raman mapping images of $I_{\mathrm{G}} / I_{2 \mathrm{D}}$ ratio (f) and $\mathrm{FWHM}_{2 \mathrm{D}}(\mathrm{g})$ of the transferred graphene grown at $1000{ }^{\circ} \mathrm{C}$.

Thickness and uniformity of transferred graphene films were assessed by Raman spectroscopy. As seen in Fig. 3e, the Raman spectra of the graphene films show a low $I_{\mathrm{G}} / I_{2 \mathrm{D}}$ ratio of $\sim 0.4$ for both 900 and $1000{ }^{\circ} \mathrm{C}$-grown samples. The 2D band located at $\sim 2685 \mathrm{~cm}^{-1}$ has narrow linewidth $\left(\mathrm{FWHM}_{2 \mathrm{D}}\right)\left(30-40 \mathrm{~cm}^{-1}\right)$ which can be fitted by single Lorentzian. These results confirm the growth of single-layer graphene [16,22,42]. However, the graphene grown at $900{ }^{\circ} \mathrm{C}$ showed the strong D band at $1350 \mathrm{~cm}^{-1}$ together with $\mathrm{D}$ ' band at $1620 \mathrm{~cm}^{-1}$, indicating the presence of significant defects and/or domain boundaries in $\sim 1 \mu \mathrm{m}$ laser spot used for the Raman measurement [24]. Raman mappings images of G and 2D band intensities of $900{ }^{\circ} \mathrm{C}-\mathrm{CVD}$ sample show that some areas have high $I_{\mathrm{G}} / I_{2 \mathrm{D}}$ ratios of $\sim 1.0$, indicating the presence of few-layer graphene domains as well as single-layer graphene (Fig. S-2). On the other hand, the graphene grown at $1000{ }^{\circ} \mathrm{C}$ showed negligible or very weak D band with $I_{\mathrm{D}} / I_{\mathrm{G}}$ ratio of $<0.05$, denoting high quality of graphene even after the transfer 
process. For more wide area inspection, we measured the Raman mapping for $20 \mu \mathrm{m} \times 20$ $\mu \mathrm{m}$ area, as shown in Fig. 3f,g. The $I_{\mathrm{G}} / I_{2 \mathrm{D}}$ ratio and $\mathrm{FWHM}_{2 \mathrm{D}}$ are $\sim 0.40$ and $30-40 \mathrm{~cm}^{-1}$, respectively, for the scanned area, confirming the uniformity of our CVD graphene. The slight variation of $I_{\mathrm{G}} / I_{2 \mathrm{D}}$ might be attributed to spatially nonuniform adhesion between the graphene film and $\mathrm{SiO}_{2} / \mathrm{Si}$ substrate during the transfer process [43]. Therefore, increasing the growth temperature is an effective way to improve the quality of single-layer graphene by suppressing the defect-induced $\mathrm{D}$ band and multi-layer graphene formation. The crystallinity of a $\mathrm{Cu}$ film is also important for uniform single-layer graphene growth.

\subsection{Orientation of graphene films}

To study the orientation of hexagonal lattice of graphene, we measured LEED for the graphene on the $\mathrm{Cu}(111)$ film with an electron beam energy of 50-300 eV. Figure 4 compares the LEED patterns of the as-grown graphene films grown at 900 and $1000{ }^{\circ} \mathrm{C}$ measured with electron energy of $140 \mathrm{eV}$ (for different energies, see Fig. S-3). Since the spot size of electron beam is around $1 \mathrm{~mm}$, a LEED pattern shows the average orientation of a graphene film. It should be noted that the as-sputtered $\mathrm{Cu}$ film did not show any diffraction patterns because the $\mathrm{Cu}$ surface is easily oxidized during transfer from a sputtering chamber to a LEED chamber. The oxidation disturbs the $\mathrm{Cu}$ surface, and the periodicity of $\mathrm{Cu}(111)$ surface is lost upon oxidation. However, when graphene covers the $\mathrm{Cu}$ surface, we could observe the clear diffraction patterns, as shown in Figs. 4 and S-3. This indicates that a graphene film prevents the $\mathrm{Cu}$ from surface oxidation, giving the diffractions from both graphene and $\mathrm{Cu}(111)$ surface.

In the case of $900{ }^{\circ} \mathrm{C} \mathrm{CVD}$, bright spots are located at the hexagonal vertexes which correspond to fcc(111) structure of $\mathrm{Cu}$ film. This is consistent with the above synchrotron XRD and EBSD measurements. Our $I-V$ measurements indicate that weak diffraction spots observed at the present energy are originated in graphene [35]. In addition, the close look at the bright spots indicate that they contain both the diffractions from $\mathrm{Cu}(111)$ and graphene with the $\mathrm{Cu}$ diffraction spots locating slightly closer to the center. This originates from the difference in lattice constants of graphene and $\mathrm{Cu}(111)$ (lattice constants of graphene and 
$\mathrm{Cu}(111)$ are $2.46 \AA$ and $2.56 \AA$, respectively). The observed LEED pattern indicates that there are two sets of graphene orientations; one with the same orientation with the underneath $\mathrm{Cu}(111)$ lattice and another with $30^{\circ}$-rotation (see Fig. 4c). We, thus, speculate that the as-grown graphene film consists of two rotational domains. The presence of rotational domains may bring a significant amount of domain boundaries which are supposed to give the observed D band (Fig. 3e).

When the graphene was grown at $1000{ }^{\circ} \mathrm{C}$, the diffraction from the $30^{\circ}$-rotated graphene domain disappeared (Fig. 4b), denoting complete match of single-layer graphene to the underlying $\mathrm{Cu}(111)$. In addition, clear satellites assigned to moiré structure were observed. The moiré pattern results from the small lattice mismatch between graphene and $\mathrm{Cu}(111)$ surface [44], and it also indicates sufficiently large graphene domain size. Further analysis of the moiré pattern, shown in Fig. S-4, suggests $(8 \times 8)$ structure assuming the thermal expansion difference of $7 \%$. At $900{ }^{\circ} \mathrm{C}$, however, the moiré pattern was not observed probably due to the coexistence of two rotated graphene domains and small domain size of graphene grown at $900{ }^{\circ} \mathrm{C}$. The origin of the observed temperature-dependent graphene orientations will be discussed later.
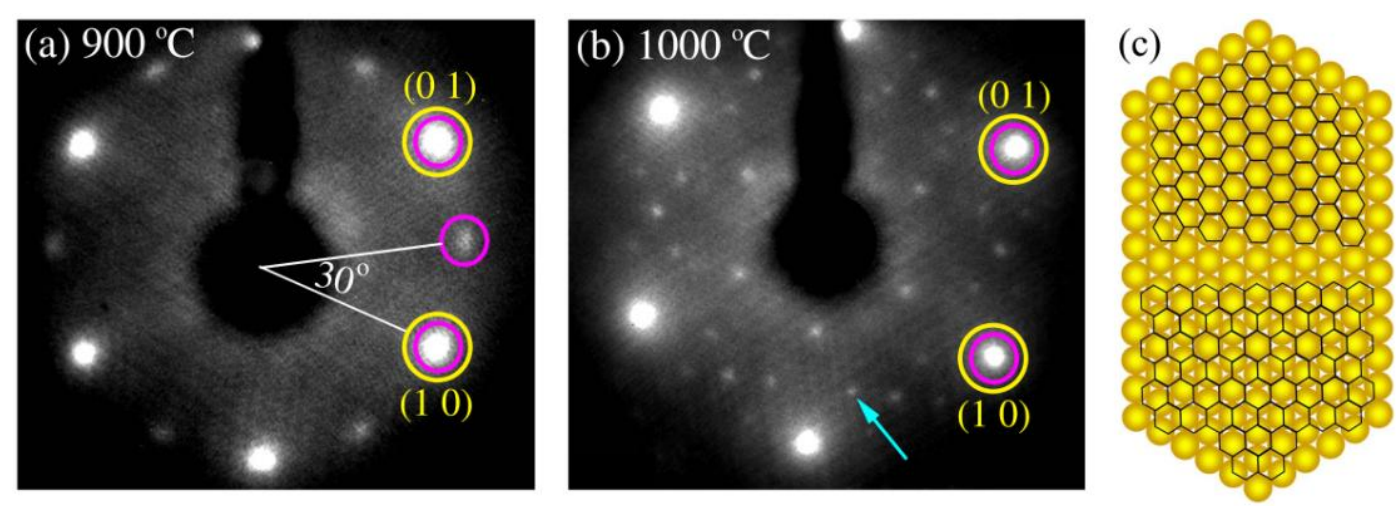

Fig. 4 LEED patterns of as-grown graphene/Cu/sapphire samples grown at $900{ }^{\circ} \mathrm{C}$ (a) and $1000{ }^{\circ} \mathrm{C}$ (b). The beam energy is $140 \mathrm{eV}$. The pink and yellow circles indicate the diffraction spots of graphene and $\mathrm{Cu}(111)$, respectively. The arrow in (b) indicates moiré pattern. (c) Illustration of atomic configuration of graphene films on $\mathrm{Cu}$ (111) with crystallographic orientation rotated by angles of $0^{\circ}$ (upper) and $30^{\circ}$ (below). The graphene film grown at $900{ }^{\circ} \mathrm{C}$ has both orientations, while the film grown at $1000{ }^{\circ} \mathrm{C}$ has only $0^{\circ}$ rotation. 


\subsection{Carbon isotope-labeled CVD}

To investigate the growth mechanism of graphene under atmospheric pressure CVD, we performed carbon isotope labeled CVD to track the carbon atoms during the graphene growth process for the different growth temperatures. We introduced ${ }^{13} \mathrm{CH}_{4}$ in the first $0-3 \mathrm{~min}$ and ${ }^{12} \mathrm{CH}_{4}$ in the successive 3-10 min into reaction chamber during CVD. Figure 5 shows the Raman data of transferred graphene grown at $900{ }^{\circ} \mathrm{C}$. The Raman spectra showed two separated $\mathrm{G}$ bands as well as two separated 2D bands (Fig. 5c,f). The $\mathrm{G}$ and 2D bands at $1520 \mathrm{~cm}^{-1}$ and $\sim 2585 \mathrm{~cm}^{-1}$, respectively, correspond to the pure ${ }^{13} \mathrm{C}$-graphene, while the peaks at $\sim 1570 \mathrm{~cm}^{-1}$ and $\sim 2660 \mathrm{~cm}^{-1}$ indicate the formation of isotopically-mixed graphene. The actual composition of the carbon isotopes is estimated to be ${ }^{12} \mathrm{C}-77 \%$ and ${ }^{13} \mathrm{C}-23 \%$ based on the following equation [45]:

$$
\omega=\omega_{12}\left[m_{12} /\left(n_{12} m_{12}+n_{13} m_{13}\right)\right]^{1 / 2}
$$

where, $\omega_{12}$ is the Raman mode frequency of pure ${ }^{12} \mathrm{C}$-graphene, $n_{12}$ and $n_{13}$ are the atomic fractions of ${ }^{12} \mathrm{C}$ and ${ }^{13} \mathrm{C}$, and $m_{12}$ and $m_{13}$ are the atomic masses of ${ }^{12} \mathrm{C}$ and ${ }^{13} \mathrm{C}$, respectively. It is noted that Raman spectra of the graphene films do not show any bands of pure ${ }^{12} \mathrm{C}$-graphene domains. Thus, it is likely that the initially introduced ${ }^{13} \mathrm{C}$ atoms form pure ${ }^{13} \mathrm{C}$-graphene domains before introducing ${ }^{12} \mathrm{CH}_{4}$. In addition, we found that the $I_{\mathrm{G}} / I_{2 \mathrm{D}}$ ratio is generally higher for the pure ${ }^{13} \mathrm{C}$-graphene than the isotopically mixed graphene (e.g. measured point $\mathrm{A}$ in Fig. 5). This suggests that the ${ }^{13} \mathrm{C}$-graphene partly contains few layer domains. Therefore, we speculate that initially introduced ${ }^{13} \mathrm{C}$ atoms segregate from grain boundaries remaining on the $\mathrm{Cu}$ surface during heating at $900{ }^{\circ} \mathrm{C}$. This is supported by the fact that graphene is strongly dependent on the CVD time for $900{ }^{\circ} \mathrm{C}$, which indicates that $\mathrm{Cu}$ surface has more grain boundaries during the initial growth period (see Fig. S-5). On the other hand, the ${ }^{13} \mathrm{C}-{ }^{12} \mathrm{C}$ mixed graphene is uniform and mainly single-layer. We infer that the ${ }^{13} \mathrm{C}$ and ${ }^{12} \mathrm{C}$ atoms exchange at the $\mathrm{Cu}$ surface which involves many dynamic processes, such as catalytic $\mathrm{CH}_{4}$ decomposition, surface carbon diffusion, dissolution of carbon atoms into the $\mathrm{Cu}$ film, removal of surface carbon atoms by hydrogen, healing the $\mathrm{Cu}$ surface, and segregation of graphene. It is noted that the present graphene growth mechanism is 
different from the surface adsorption mechanism proposed for the vacuum CVD on polycrystalline $\mathrm{Cu}$ where the ${ }^{12} \mathrm{C}$ and ${ }^{13} \mathrm{C}$ atoms are not mixed at all [45].

When the growth temperature was increased to $1000{ }^{\circ} \mathrm{C}$, whole graphene showed the isotopically mixed $\mathrm{G}$ and $2 \mathrm{D}$ bands, as displayed in Fig. 6. In addition, the composition is quite uniform as seen in the mapping images. These data represent that the exchange of ${ }^{13} \mathrm{C}$ and ${ }^{12} \mathrm{C}$ atoms occurred more frequently than at $900{ }^{\circ} \mathrm{C}$ CVD. As shown in Fig. S-6, performing CVD for $3 \mathrm{~min}$ still gave uniform, single-layer graphene, indicating the $\mathrm{Cu}$ surface is fully covered with graphene in the first $3 \mathrm{~min}$. Also differently from the case at $900{ }^{\circ} \mathrm{C}$, independence of graphene growth on the CVD time at $1000{ }^{\circ} \mathrm{C}$ reveals relatively fewer grain boundaries at the initial growth stage. This may be another reason why the initially introduced ${ }^{13} \mathrm{C}$ atoms did not form the pure ${ }^{13} \mathrm{C}$-graphene domains. We further investigated the Raman result of the different ${ }^{13} \mathrm{CH}_{4}{ }^{12} \mathrm{CH}_{4}$ supply timing shown in Figs. S-7,8 (8 $\min { }^{13} \mathrm{CH}_{4}$, followed by $2 \min { }^{12} \mathrm{CH}_{4}$ ); the longer ${ }^{13} \mathrm{CH}_{4}$ supply time still resulted in the isotopically mixed graphene without forming pure ${ }^{13} \mathrm{C}$-graphene. Therefore, it is suggested that the graphitization occurs during the rapid cooling, considering the complete mixing of ${ }^{13} \mathrm{C}-{ }^{12} \mathrm{C}$ isotopes.

To further study the growth mechanism of single-layer graphene on $\mathrm{Cu}(111)$, we supplied $\mathrm{CH}_{4}$ for short times, $10 \mathrm{sec}, 30 \mathrm{sec}$, and $60 \mathrm{sec}$. The result is summarized in Fig. S-9. The number of graphene domains increased with increasing $\mathrm{CH}_{4}$ supply time, while the domain size did not significantly increase with the supply time. The present result suggests the different growth model proposed for vacuum CVD, in which graphene's domains size gradually increases with the CVD time [45]. Therefore, we speculate that the graphene nucleation (or graphitization) occurs during the cooling process in which the total area of the segregated graphene is correlated to the total amount of supplied $\mathrm{CH}_{4}$. In this model, the catalytically decomposed carbon atoms stay on the $\mathrm{Cu}$ surface during CVD but not completely graphitized. Similar to other CVD works [15,27], the cooling rate strongly influenced graphene films; slow cooling gave preferential formation of multi-layer graphene flakes (not shown here). This result suggests that the graphene growth on our $\mathrm{Cu}$ film is not the simple surface reaction for the atmospheric CVD. We also think that even for 
atmospheric CVD the $\mathrm{CH}_{4}$ concentration supplied during CVD influences the growth dynamics of graphene on the $\mathrm{Cu}$ surface. Further study like in-situ growth measurement is necessary for better understanding of the growth mechanism. After $60 \mathrm{sec} \mathrm{CH}_{4}$ supply, more than half of the $\mathrm{Cu}$ surface area was covered with the graphene domains. This is consistent with the whole surface coverage observed after 3 min CVD (see Fig. S-6). Thus, the carbon isotope labeling experiments $\left({ }^{13} \mathrm{CH}_{4}\right.$ 0-3 $\mathrm{min},{ }^{12} \mathrm{CH}_{4}$ 3-8 min) shown in Fig. 6 support the surface exchange reaction of ${ }^{13} \mathrm{C}-{ }^{12} \mathrm{C}$ atoms at $1000{ }^{\circ} \mathrm{C}$. In addition, after $60 \mathrm{sec}$, hexagonal graphene domains appeared on the $\mathrm{Cu}$ surface. Such hexagonal domain structure was reported recently for the atmospheric CVD [46,47].
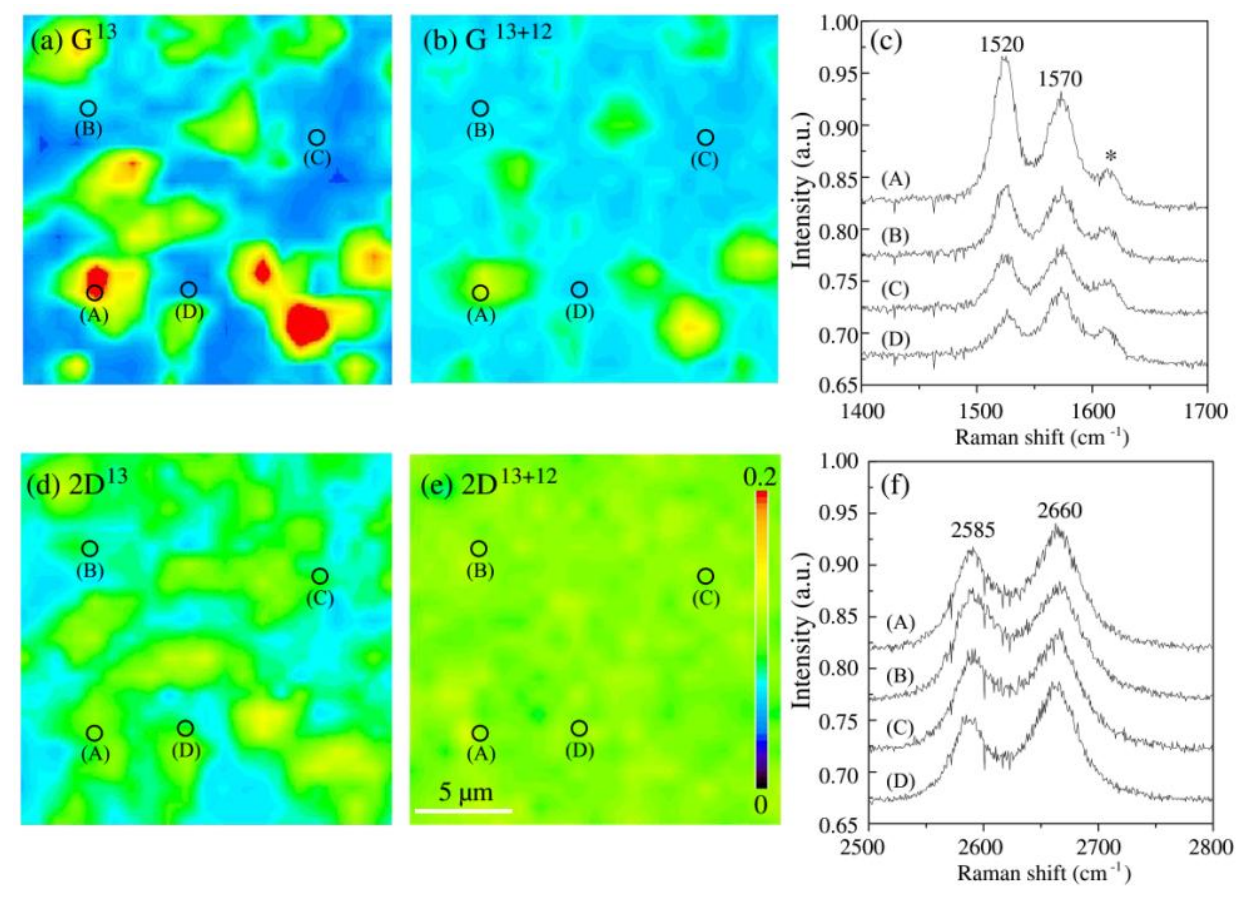

Fig. 5 Raman measurement of transferred graphene with ${ }^{13} \mathrm{CH}_{4}(0-3 \mathrm{~min})$ and ${ }^{12} \mathrm{CH}_{4}(3-10$ min) grown from $900{ }^{\circ} \mathrm{C} \mathrm{CVD}$. Raman mapping images of $\mathrm{G}$ bands at $1520 \mathrm{~cm}^{-1}$ (a) and $1570 \mathrm{~cm}^{-1}$ (b). (c) Raman spectra of $\mathrm{G}$ bands of 4 random points marked with (A), (B), (C), and (D) in the same region as (a) and (b). Raman mapping images of $2 \mathrm{D}$ bands at $2585 \mathrm{~cm}^{-1}$ (d) and $2660 \mathrm{~cm}^{-1}$ (e). (f) Raman spectra of 2D bands of 4 random points in the same region as (d) and (e). The symbol "*” at around $1620 \mathrm{~cm}^{-1}$ in (c) indicates the defect-related D' peak. 

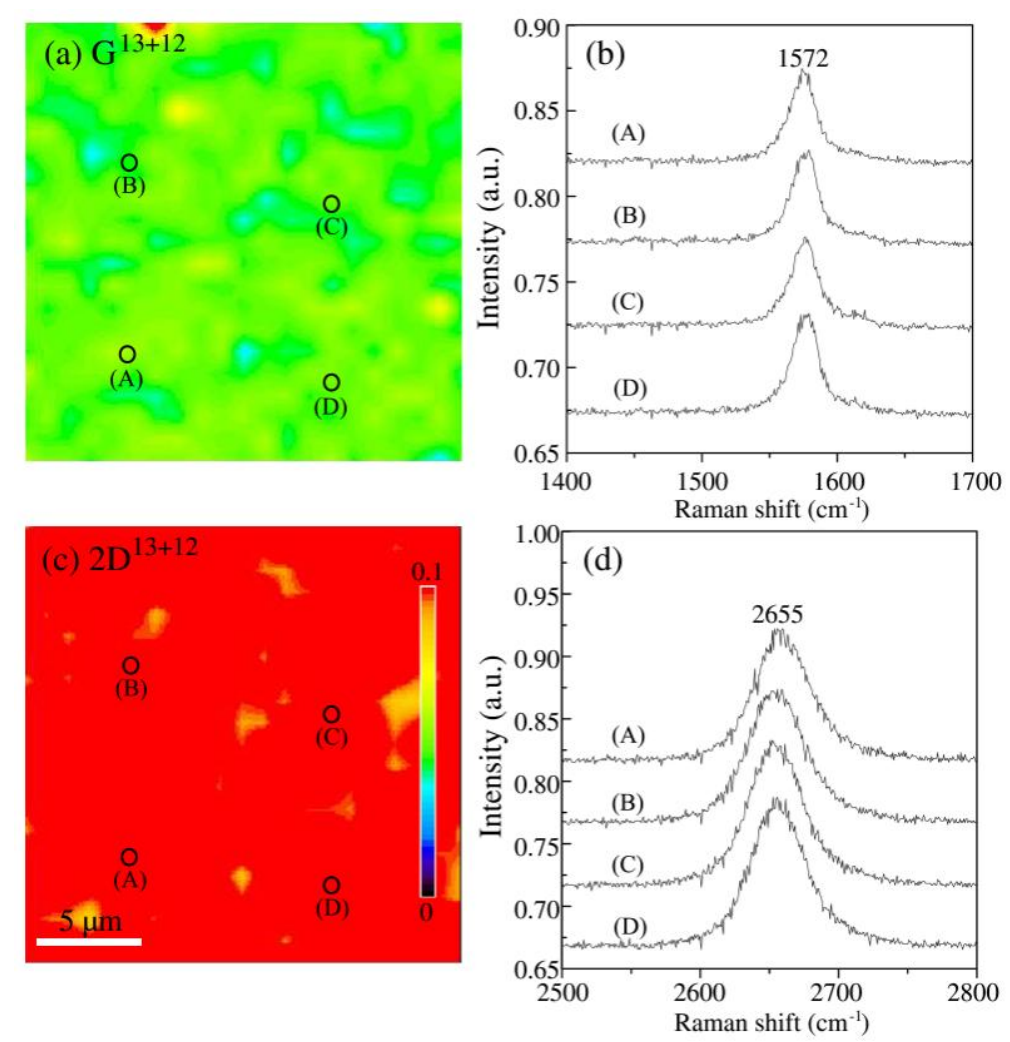

Fig. 6 Raman measurement of transferred graphene with ${ }^{13} \mathrm{CH}_{4}(0-3 \mathrm{~min})$ and ${ }^{12} \mathrm{CH}_{4}$ (3-10 min) grown from $1000{ }^{\circ} \mathrm{C} \mathrm{CVD}$. Raman mapping images of $\mathrm{G}$ bands at $1570 \mathrm{~cm}^{-1}$ (a) and $2 \mathrm{D}$ bands at $2655 \mathrm{~cm}^{-1}$ (c). (b) and (d) are Raman spectra of $\mathrm{G}$ and 2D bands at 4 random points marked with (A), (B), (C), and (D) in the same region as (a) and (b), respectively.

Finally, we discuss the origin of different orientations of graphene films observed for 900 and $1000{ }^{\circ} \mathrm{C} \mathrm{CVD}$. From the previous isotope labeling experiments, carbon atoms on the $\mathrm{Cu}$ surface is suggested to have higher energies, stimulating thermal diffusion on the $\mathrm{Cu}$ surface as well as exchange reaction of carbon atoms between the $\mathrm{Cu}$ surface and vapor-supplied $\mathrm{CH}_{4}$ gas at $1000^{\circ} \mathrm{C}$. Therefore, we propose that the as-grown graphene can have energetically the most stable orientation, which is commensurate structure with the underneath $\mathrm{Cu}(111)$ lattice. On the other hand, at $900{ }^{\circ} \mathrm{C}$, the sub-stable $30^{\circ}$-oriented graphene domains also 
grow due to insufficient thermal energy. Another possible reason for the observed different orientations is the different $\mathrm{Cu}$ surface morphology at 900 and $1000{ }^{\circ} \mathrm{C}$. At $900{ }^{\circ} \mathrm{C}$, there are significant amount of grain boundaries in the $\mathrm{Cu}$ film in the initial 3 minutes, as demonstrated in Fig. S-5, and the graphene nucleated from the boundaries may have rotated domains.

\section{Conclusions}

We demonstrate that orientation-controlled, large-area, and high-quality single-layer graphene can be grown on heteroepitaxial $\mathrm{Cu}(111)$ film deposited on c-plane sapphire by atmospheric pressure CVD. Compared to previous CVD results using heteroepitaxial $\mathrm{Co}, \mathrm{Ni}$, $\mathrm{Ru}$ films, the graphene grown on the present $\mathrm{Cu}(111)$ film shows much weaker $\mathrm{D}$ band, indicating the growth of high quality graphene and ease of the chemical etching without introducing clear damage to graphene. In addition, we find the temperature-dependent domain orientation of single-layer graphene. At relatively low growth temperature $\left(900{ }^{\circ} \mathrm{C}\right)$, two orientations are observed, but higher temperature $\left(1000{ }^{\circ} \mathrm{C}\right)$ gives rise to only one orientation which is consistent with the underlying $\mathrm{Cu}(111)$ lattice. Carbon isotope labeled CVD indicates the facile and dynamic exchange of surface carbon atoms on the $\mathrm{Cu}(111)$ which is quite different from the vacuum CVD system. The observed temperature-dependent orientation of graphene films is explained by different thermal energies and $\mathrm{Cu}$ surface structures. Our findings gives new insight into the growth mechanism of single-layer graphene on the $\mathrm{Cu}$ catalyst, and our approach will be further developed to grow extremely high-quality graphene for future carbon electronics applications.

\section{Acknowledgements}

This work is supported by JSPS Funding Program for Next Generation World-Leading Researches (NEXT Program) and PRESTO, Japan Science and Technology. Synchrotron XRD and TEM measurements were performed at the SAGA Light Source (No. 100533N) and Fukuryo Semiconductor Engineering Co. respectively. 


\section{REFERENCES}

[1] Novoselov KS, Geim AK, Morozov SV, Jiang D, Zhang Y, Dubonos SV, et al. Electric field effect in atomically thin carbon films. Science 2004;306:666-669.

[2] Zhang Y, Tan JW, Stormer HL, Kim P. Experimental observation of the quantum Hall effect and Berry's phase in graphene. Nature 2005;438:201-4.

[3] Bolotin KI, Sikes KJ, Jiang Z, Klima M, Fudenberg G, Hone J, et al. Ultrahigh electron mobility in suspended graphene. Solid State Commun 2008;146:351-5.

[4] Lee C, Wei X, Kysar JW, Hone J. Measurement of the elastic properties and intrinsic strength of monolayer graphene. Science 2008;321:385-8.

[5] Schwierz F. Graphene transistors. Nat Nanotech 2010;5:487-96.

[6] Eda G, Fanchini G, Chhowalla M. Large-area ultrathin films of reduced graphene oxide as a transparent and flexibleelectronic material. Nat Nanotech 2008;3:270-4.

[7] Blake P, Brimicombe PD, Nair RR, Booth TJ, Jiang D, Schedin F, et al. Graphene-based liquid crystal device. Nano Lett 2008;8:1704-8.

[8] Stoller MD, Park S, Zhu Y, An J, Ruoff RS. Graphene-based ultracapacitors. Nano Lett 2008;8:3498-3502.

[9] Geim AK, Novoselov KS. The rise of graphene. Nat Mater 2007; 6: 183-191.

[10] Berger C, Song Z, Li X, Wu X, Brown N, Naud C, et al. Electronic confinement and coherence in patterned epitaxial graphene. Science 2006;312:1991-6.

[11] Emtsev KV, Bostwick A, Horn K, Jobst J, Kellogg GL, Ley L, et al. Towards wafer-size graphene layers by atmospheric pressure graphitization of silicon carbide. Nat Mater 2009;8:203-7.

[12] Tung VC, Allen MJ, Yang Y, Kaner RB. High-throughput solution processing of large-scale graphene. Nat Nanotech 2009;4:25-29.

[13] Hernandez Y, Nicolosi V, Lotya M, Blighe FM, Sun ZY, De S, et al. High-yield production of graphene by liquid-phase exfoliation of graphite. Nat Nanotech 2008,3,563-8.

[14] Wang S, Ang PK, Wang Z, Tang ALL, Thong JTL, Loh KP. High mobility, printable, and solution-processed graphene electronics. Nano Lett 2010;10:92-8. 
[15] Yu Q, Lian J, Siriponglert S, Li H, Chen YP, Pei SS. Graphene segregated on Ni surfaces and transferred to insulators. Appl Phys Lett 2008;93:113103-1-3.

[16] Reina A, Jia X, Ho J, Nezich D, Son H, Bulovic V et al. Large area, few-layer graphene films on arbitrary substrates by chemical vapor deposition. Nano Lett 2009;9:30-5.

[17] Arco LGD, Zhang Y, Kumar A, Zhou C. Synthesis, transfer, and devices of single- and few-layer graphene by chemical vapor deposition. IEEE Trans Nanotech 2009;8:135-8.

[18] Kim KS, Zhao Y, Jang H, Lee SY, Kim JM, Kim KS, et al. Large-scale pattern growth of graphene films for stretchable transparent electrodes. Nature 2009;457:706-10.

[19] Miyata Y, Kamon K, Ohashi K, Kitaura R, Yoshimura M, Shinohara H. A simple alcohol-chemical vapor deposition synthesis of single-layer graphenes using flash cooling. Appl Phys Lett 2010;96:263105-1-3.

[20] Chae SJ, Güneş F, Kim KK, Kim ES, Han GH, Kim SM, et al. Synthesis of large-area graphene layers on poly-nickel substrate by chemical vapor deposition: wrinkle formation. Adv Mater 2009;21:1-6.

[21] Kondo D, Sato S, Yagi K, Harada Y, Sato M, Nihei M, et al. Low-temperature synthesis of graphene and fabrication of top-gated field effect transistors without using transfer processes. Appl Phys Exp 2010;3:25102-1-3.

[22] Li X, Cai W, An JH, Kim S, Nah J, Yang DX, et al. Science 2009; 324: 1312-4.

[23] Levendorf M, Ruiz-Vargas C, Garg S, Park J. Transfer-free batch fabrication of single layer graphene transistors. Nano Lett 2009;9:4479-83.

[24] Lee, Y. H.; Lee, J. H. Scalable growth of free-standing graphene wafers with copper $(\mathrm{Cu})$ catalyst on $\mathrm{SiO}_{2} / \mathrm{Si}$ substrate: Thermal conductivity of the wafers. Appl Phys Lett 2010;96:083101-1-3.

[25] Bae S, Kim H, Lee Y, Xu X, Park JS, Zheng Y, et al. Roll-to-roll production of 30-inch graphene films for transparent electrodes. Nat Nanotech 2010;5:574-8.

[26] Gao L, Ren W, Zhao J, Ma LP, Che Z, Cheng HM. Efficient growth of high-quality graphene films on $\mathrm{Cu}$ foils by ambient pressure chemical vapor deposition. Appl Phys Lett 2010;97:183109-1-3. 
[27] Reina A, Thiele S, Jia X, Bhaviripudi S, Dresselhaus MS, Schaefer JA. et al. Growth of large-area single- and bi-layer graphene by controlled carbon precipitation on polycrystalline Ni surfaces. J Nano Res 2009;2:509-16.

[28] Huang PY, Ruiz-Vargas CS, Zande AM, Whitney WS, Levendorf MP, Kevek JW, et al. Grains and grain boundaries in single-layer graphene atomic patchwork quilts. Nature 2011;469:389-93.

[29] Gamo Y, Nagashima A, Wakabayashi M, Terai M, Oshima C. Atomic structure of monolayer graphite formed on Ni(111). Surf Sci 1997;374:61-4.

[30] Usachov D, Dobrotvorskii AM, Varykhalov A, Rader O, Gudat W, Shikin AM. Experimental and theoretical study of the morphology of commensurate and incommensurate graphene layers on Ni single-crystal surfaces. Phys Rev B 2008;78:85403-1-8.

[31] Sutter PW, Flege JI, Sutter EA. Epitaxial graphene on ruthenium. Nat Mater 2008;7:406-411.

[32] Marchini S, Günther S, Wintterlin J. Scanning tunneling microscopy of graphene on Ru(0001). Phys Rev B 2007;76:75429-1-9.

[33] N'Diaye AT, Bleikamp S, Feibelman PJ, Michely T. Two-dimensional Ir cluster lattice on a graphene moiré on $\operatorname{Ir}(111)$. Phys. Rev. Lett. 2006;97:215501-1-4.

[34] Ago H, Tanaka I, Orofeo CM, Tsuji M, Ikeda K. Patterned growth of graphene over epitaxial catalyst. Small 2010;6:1226-33.

[35] Ago H, Ito Y, Mizuta N, Yoshida K, Hu B, Orofeo CM, et al. Epitaxial chemical vapor deposition growth of single-layer graphene over cobalt film crystallized on sapphire. ACS Nano 2010,;4:7407-14.

[36] Iwasaki T, Park HJ, Konuma M, Lee DS, Smet JH, Starke U. Long-range ordered single-crystal graphene on high-quality heteroepitaxial Ni thin films grown on $\mathrm{MgO}(111)$. Nano Lett 2011;11:79-84.

[37] Sutter PW, Albrecht PM, Sutter EA. Graphene growth on epitaxial Ru thin films on sapphire. Appl Phys Lett 2010;97:213101-1-3.

[38] Giovannetti G, Khomyakov PA, Brocks G, Karpan VM, van den Brink J, Kelly PJ. Doping graphene with metal contacts. Phys Rev Lett 2008;101:26803-1-4. 
[39] Bialas H, Knoll E. Heteroepitaxy of copper on sapphire under uhv conditions. Vacuum 1994;45:959-66.

[40] Bialas H, Heneka K. Epitaxy of fee metals on dielectric substrates. Vacuum 1994;45:79-87.

[41] Mun JH, Hwang C, Lim SK, Cho BJ. Optical reflectance measurement of large-scale graphene layers synthesized on nickel thin film by carbon segregation. Carbon 2010;48:447-451.

[42] Ferrari AC, Meyer JC, Scardaci V, Casiraghi C, Lazzerui M, Mauri F, et al. Raman spectrum of graphene and graphene layers. Phys Rev Lett 2006;97:187401-1-4.

[43] Cao H, Yu Q, Colby R, Pandey D, Park CS, Lian J, et al. Large-scale graphitic thin films synthesized on Ni insulators: Structural and electronic properties. J Appl Phys 2010;107:44310-1-7.

[44] Gao L, Guest JR, Guisinger NP. Epitaxial graphene on $\mathrm{Cu}(111)$. Nano Lett 2010;10:3512-6.

[45] Li X, Cai W, Colombo L, Ruoff RS. Evolution of graphene growth on Ni and Cu by carbon isotope labeling. Nano Lett 2009;9:4268-72.

[46] Robertson AW, Warner JH. Hexagonal single crystal domains of few-layer graphene on copper foils. Nano Lett 2011;11:1182-1189.

[47] Yu Q, Jauregui LA, Wu W, Colby R, Tian J, Su Z, et al. Control and characterization of individual grains and grain boundaries in graphene grown by chemical vapour deposition. Nat Mater 2011;10:443-449. 